\title{
ÉTICA E MORAL COMO MODOS DE PRODUÇÃO DE SUBJETIVIDADE ${ }^{1}$
}

\author{
Rodrigo Gelamo PELLOSO ${ }^{2}$ \\ Maria da Graça Chamma Ferraz e FERRAZ ${ }^{3}$
}

- RESUMO: Deleuze e Guattari entendem as idéias de Ética e Moral como movimentos produtores de realidade psicossocial ou sentidos de produção da vida psicossocial. Buscamos entender como os modos de funcionamento psicossociais produzem sentidos e podem ser captados nas práticas psicossociais éticas e morais. Nossa intenção é demonstrar, a partir da literatura kafkiana, os modos de subjetivação ética e moral.

- PALAVRAS-CHAVE: sujeito, produção de subjetividade, processo de subjetivação, ética e moral.

\section{Introdução}

Deleuze e Guattari entendem as idéias de Ética e Moral como movimentos produtores de realidade psicossocial ou sentidos de produção da vida psicossocial que agenciam, em seu percurso, maiores ou menores espaços. O espaço psicossocial, neste sentido, constitui-se do chamado indivíduo e de suas conexões sociais, econômicas, lingüísticas e culturais. Esses movimentos psicossociais podem produzir desde a manutenção de um estado de coisas até a recriação da subjetividade:

A subjetividade é produzida por agenciamentos de enunciação. Os processos de subjetivação, de semiotização - ou seja, toda a produção de sentido, de eficiência

1 Artigo recebido em 05/2005; aprovado para publicação em 06/2005.

2 Mestre em Filosofia e doutorando em Educação - PPG - UNESP/Marília; gelamo@fateb.br

3 Doutora em Psicologia e professora da pós-graduação - UNESP/Marília; dagraca@flash.tv.br 
semiótica - não são centrados em agentes individuais (no funcionamento de instâncias intrapsíquicas, egóicas, microssociais), nem em agentes grupais. (GUATTARI; ROLNIK. 1986. p.31)

Podemos entender os movimentos psicossociais como máquinas de produção da subjetividade fabricadas e modeladas essencialmente no registro social:

As máquinas de produção de subjetividade variam. Em sistemas tradicionais, por exemplo, a subjetividade é fabricada por máquinas mais territorializadas, na escala de uma etnia, de uma corporação profissional, uma casta. (GUATTARI; RONIK. 1986. p.25)

Tais movimentos podem ser pensados em dois sentidos: (a) de reprodução dos modelos sociais estandardizados; ou (b) de reinvenção dos modos de produção. Os primeiros (de reprodução) podem ser relacionados aos movimentos morais, e os últimos (de reinvenção), aos movimentos éticos.

Os movimentos morais reproduzem os territórios (papéis sociais, modos de produção do psiquismo, etc.), efetuando um sentido edipiano de obediência a um lugar de interdição dos movimentos subversores do estado de coisas. "Acredita-se freqüentemente que o Édipo é fácil, é dado. Mas não é assim: Édipo supõe uma fantástica repressão das máquinas desejantes" (DELEUZE; GUATTARI, 1976. p. 17). Os movimentos éticos são condizentes com modos de gerenciamento do psiquismo e da instância social desterritorializante dos modelos estandardizados. "O esquizofrênico é o produtor universal. Não há lugar, aqui, para distinguir o produzir de seu produto." (DELEUZE; GUATTARI. 1976, p. 21). Deleuze e Guattari oferecem instrumentos adequados à compreensão desse modo de produção diferenciado do edipiano.

Como conseqüência da adoção desse referencial de análise, estaremos pensando o movimento de produção de subjetividade, ${ }^{4}$ que instaura práticas e realidades sociais singulares (novas dobras sociais; novos modos de ser e de realizar). Pensamos poder investigar neste artigo, por meio da literatura kafkiana, os modos de subjetivação produtores de realidades éticas e morais. Para isso, vamos pôr em oposição à idéia de Ética a idéia de Moral.

Pensamos, com Deleuze e Guattari, que "a ética tem um valor supremo de invenção", como afirma Baremblitt (1998) a partir dos autores citados, e

4 Para Deleuze e Guattari o que existe é "simplesmente uma produção de subjetividade. Não somente uma produção de subjetividade individuada - subjetividade dos indivíduos - mas uma produção de subjetividade social, uma produção de subjetividade que se pode encontrar em todos os níveis da produção de consumo. E mais ainda na produção de subjetividade inconsciente" (GUATTARI, ROLNIK. 1986, p.16). 
que "tal inventividade tem como método, a intuição, o uso disjunto das faculdades (...) a plena consideração do acaso para o exercício de pensares sem fundamento, sem sistemática, sem meta-categorias" (1998, p.45). Ainda para Baremblitt, a proposta de Deleuze/Guattari:

(...) é uma política da avaliação, da resolução e do ato sempre singulares, criados para cada situação, produtos da Vontade de Potência e da desconstrução dos valores imperantes, a serviço da inovação permanente, jamais subordinada a algum Imperativo Categórico Universal ou eterno, nem baseado em Princípios Transcendentes. (1998. p.45)

Temos considerado que o sentido de produção pode ser captado nas práticas psicossociais. Por práticas psicossociais temos entendido exatamente aquilo que os homens fazem em seu cotidiano. Quando pensamos que essa prática é a própria produção humana em todas as instâncias (psicológicas, culturais, políticas, etc.) de sua existência, parece pertinente considerar a literatura como uma prática produtora de subjetividade e, portanto, produtora de realidade psicossocial. Sendo assim, entendemos a literatura como um movimento agenciador de intensidades psicossociais.

Quando falamos num sentido ético e num sentido moral de subjetivação, referimo-nos a modos de produção psicológicos e sociais. Falamos de um modo de produção ético referente a um exercício de atualização das intensidades, de um vir-a-ser psicológico e social: "erguendo o desejo, ao invés de rebatê-lo, deslocando-o no tempo, desterritorializando-o, fazendo proliferar suas conexões, fazendo-o passar para outras intensidades" (DELEUZE; GUATTARI. 1977, p.8). Referimo-nos também a um movimento de reprodução de realidades e sentidos psicológicos e sociais, o qual chamamos de modos de produção moral: "um bloqueio funcional, uma neutralizaÇão do desejo experimental (...) desejo que não pode mais usufruir a não ser de sua própria submissão". (DELEUZE; GUATTARI. 1977, p.8).

\section{De como entramos na obra de Kafka}

A primeira pergunta que nos fizemos, ao ler Metamorfose e Carta ao Pai, foi: "Como entrar na obra de Kafka?" (DELEUZE; GUATTARI. 1977, p.7). Esta pergunta é, também, a primeira que Deleuze e Guattari fazem a si mesmos na obra: Kafka para uma literatura menor. Esta é a pergunta de entrada para a obra de Kafka. Para os referidos pensadores, a obra kafkiana "Trata-se de um rizoma, de uma toca" (DELEUZE; GUATTARI. 1977, p.7) e, por este motivo, tem entradas múltiplas. Deleuze e Guattari provavelmente incorporam o termo rizoma das ciências biológicas, mais especificamente das agrícolas e botânicas. Esse termo designa uma planta que tem um sis- 
tema radicular complexo, com tantas conexões que não se sabe em que lugar começa e em que lugar termina o sistema radicular. As plantas rizomáticas têm raízes e caules tanto subterrâneos (escondidos, obscuros) quanto aéreos (que aparecem ao olhar). Tudo (caules aéreos e subterrâneos, raízes aéreas e subterrâneas) está conectado com tudo, formando, assim, um emaranhado de caminhos, de sentidos.

No Brasil, podemos citar como exemplo de planta rizomática a "tiririca", planta daninha que facilmente é encontrada nas plantações agrícolas e jardins. Essa planta é dificilmente erradicada, devido à resistência de seu sistema radicular. Quando se consegue uma ação contra o primeiro bulbo, fica cortada conexão com os demais, mas antes continuam a se reproduzir independentemente do primeiro, formando assim uma nova planta.

A obra de Kafka possui inúmeras portas de entrada e de saída: algumas portas aparentes e outras tão obscuras que temos que ir ao fundo do sistema radicular para encontrar as conexões. Por este motivo, poderíamos escolher qualquer porta de entrada, por exemplo, entrar pelas figuras animais, a partir das quais Kafka expressa o devir animal, considerado por Deleuze e Guattari: "o tornar-se animal nada tem de metafórico. Nenhum simbolismo, nenhuma alegoria. Não é também o resultado de um erro ou de uma maldição, o efeito de uma culpa" (DELEUZE; GUATTARI. 1977, p.25). Poderíamos entrar pela idéia esquizoanalítica de uma literatura kafkiana, que escapa aos modelos estandardizados, ou seja, uma literatura menor, em linguagem menor.

Para Deleuze e Guattari

Uma literatura menor não é a de uma língua menor, mas antes a que uma minoria faz em uma língua maior. No entanto, a primeira característica é, de qualquer modo, que a língua aí é modificada por um forte coeficiente de desterritorialização. (DELEUZE; GUATTARI. 1977, p.25)

Desse modo, os autores explicam essa idéia de literatura menor dizendo que Kafka "faz passar" uma subjetividade hebraica por uma língua "standard", como é a língua alemã, própria à comunicação da sensibilidade anglosaxônica. O povo hebreu constrói uma história fundada no nomadismo, o que lhe permite modos de ser e sentir singulares. O território hebreu não é coincidente com espaços físicos, com uma língua ou uma organização social específica, mas com espaços existenciais, com uma sensibilidade materializada em práticas religiosas e culturais. Kafka é um hebreu que afirma tragicamente essa sensibilidade nômade, que quer escapar dos territórios estandardizados. Sua obra literária é matéria de expressão de certa sensibilidade não aparentada com a sensibilidade alemã.

Poderíamos abordar a obra kafkiana também por sua dimensão onírica, tão característica. Em toda a obra de Franz Kafka, que acontece sempre em 
atmosfera onírica, as personagens, os objetos e os espaços são desterritorializados, mantendo uma relação de contigüidade com a exterioridade e o "fora" (indiferenciado, diferença, fundo de imanência). Em "O Processo" (que não vamos analisar em detalhes, nesta pesquisa), por exemplo, o tribunal é "parede-meia" com o quarto de pensão de um pintor de quadros, em uma relação incompreensível ao leitor. Como pode ser isso? É que o tribunal é desterritorializado. Ele está em toda parte, agindo pelos escaninhos. Em "O Castelo", sua construção é apenas uma impressão enganosa de totalidade. Quando o agrimensor tenta chegar ao castelo, percebe-se em um labirinto: quanto mais ele avança em direção ao castelo, mais distante fica a construção. O castelo, portanto, é um espaço desterritorializado, micropolítico. Sua constituição é pura intensidade, sentidos autoritários, estandardizados de produção da aldeia (em todas as instâncias), cujo governo está no "senhor do castelo" (o interditor, o mesmo de "Carta ao Pai").

As intensidades, os sentidos, os movimentos de realização da existência, em Kafka, não cabem nos modelos estandardizados, nas configurações semióticas ou significantes padrões. As personagens são sempre existencialmente desterritorializadas: sexualmente, socialmente, politicamente, etc. Jamais se definem neste ou naquele sentido, como o próprio Kafka, que pode ser também o Sr. K., de "O Processo", ou Gregor Samsa, de "Metamorfose".

Considerando que estamos pensando a literatura como agenciadora das intensidades (Confira, DELEUZE. 1997, p.11-16) do plano social e o sentido de produção como modo de gerenciamento dessas intensidades, parece pertinente entender a literatura kafkiana como um lugar de leitura de subjetividade. Deleuze e Guattari afirmam que a genialidade de Kafka está em "considerar que os homens e as mulheres fazem parte da máquina, não somente em seu trabalho, mas ainda em suas atividades adjacentes, em seu repouso, em seus amores, em seus protestos, suas indagações, etc." (DELEUZE; GUATTARI. 1977, p.118).

Tendo em vista que não pensamos um reconhecimento de identidades históricas nem a reprodução de papéis sociais, mas sentidos de atualização de intensidades, os "personagens-experimentais" kafkianos, tais como Gregor Samsa, o Jejuador, Sr. K., etc., parecem lugares psicossociais interessantes para análise. Por exemplo, o tornar-se animal do personagem de $\mathrm{Me}$ tamorfose

(...) é precisamente fazer o movimento, traçar a linha de fuga em toda sua positividade, ultrapassar um limiar, atingir um continuum de intensidades que não valem mais do que elas mesmas, encontrar um mundo de intensidades puras, onde todas as formas se desfazem, todas as significações também. (DELEUZE; GUATTARI. 1977, p. 20)

Pudemos pensar os personagens kafkianos como superfícies de registro de um vir-a-ser descomprometido com segmentos sociais ou limites his- 
tóricos e entendê-los como modo de gerenciamento das relações entre o homem e seu plano de produção existencial.

Pensamos certos personagens de Kafka como sentidos éticos de produção relacionados a instâncias psicossociais constituídas por sentidos morais. O romance "O Processo" nos traz o Sr. K. como um modo de produção existencial ético em relação com instâncias sociais constituídas pela moral reprodutora de modelos universais (a repartição pública, o tribunal, etc.).

Os textos de Franz Kafka permitem-nos entender os modos de funcionamento de alguns de seus personagens, bem como as realidades que estes vão criando em seus espaços psicossociais.

\section{Do que encontramos na obra de Kafka}

Certos personagens criados por Franz Kafka são movimentos de subjetivação orientados por um sentido ético e relacionam-se com instâncias psicossociais orientadas por um sentido moral. Os movimentos-personagens orientados por um sentido ético produzem em seu entorno realidades favorecedoras de novos espaços psicossociais, enquanto outras instâncias e personagens buscam conter a configuração desses novos espaços. A estes últimos, chamamos de movimentos-personagens morais.

Entendemos esse movimentos-personagens de dois modos: movimento re-criador e movimento reprodutor de realidades:

1 - O movimento desterritorializante, ${ }^{5}$ expresso em certos personagens kafkianos, é favorecedor da vida, das transformações e recriações dos espaÇos sociais.

2 - O movimento reprodutor das normas e leis, territorializante, ${ }^{6}$ expresso em outros personagens kafkianos, não é necessariamente favorece-

5 A desterritorialização, ou melhor, a esquizofrenia como processo é responsável pelos fluxos. Vejamos a citação de O Anti-Édipo: "A esquizofrenia como processo é inseparável das estases que a interrompem, ou então, que exasperam, ou ainda que a fazem girar em torno, e que a reterritorializam em neurose, em perversão, em psicose. A ponto de o processo só poder desembaraçar-se, prosseguir sozinho, e completar-se na medida em que é capaz de criar" (DELEUZE; GUATTARI. 1976. p.403). É este o sentido da desterritorialização: desembaraçar o processo a ponto de este poder criar.

6 A territorialização é o confinamento dos fluxos. Podemos notar isso nas seguintes citações de $O$ Anti-Édipo, nas quais D/G falam sobre a máquina territorial: "A máquina territorial primitiva codifica os fluxos, investe os órgãos, marca os corpos" (DELEUZE; GUATTARI. 1976. p.183) impedindo, assim, os fluxos. Outra citação que ajudaria na compreensão encontra-se na descrição da Terra territorialidade: "Terras familiares edipianadas da neurose, terras artificiais da perversão, terras asilares da psicose, como sobre elas reconquistar novamente o processo, retomar constantemente a viagem?" (DELEUZE; GUATTARI. 1976, p. 403). Esta pergunta mostra o caráter configurante da territorialização. 
dor da vida, podendo funcionar como mantenedor equivocado de espaços sociais mortíferos.

Analisamos, da vasta obra de Franz Kafka, principalmente o conto $\mathrm{Me}$ tamorfose e a Carta ao Pai. Os personagens interessantes à análise foram eleitos a partir de leitura rigorosa dessas obras. Posteriormente, procedemos a uma análise dos movimentos psicossociais efetuados por esses personagens.

Os personagens interessantes à análise foram aqueles que sugeriram um funcionamento anti-edipiano. Isto quer dizer intensidades que buscam configuração num movimento de oposição às centrais de codificação fundamentando-se em modelos estandardizados. Esses personagens foram localizados a partir de sinais de oposições (quer por ações, gestos, sentimentos, etc.) à submissão dos mesmos personagens aos poderes constituídos (quer sociais, políticos, religiosos, ou mesmo de foro institucional doméstico, tais como a família, o trabalho, etc).

Os referidos sinais foram investigados com base nos objetos teóricos deleuzoguattarianos:

- objeto hiperdesterritorializado: afirmação trágica de espaços institucionais e psicológicos, de maneira a expandi-los até a criação de pontos de subjetivação, ou seja, até a possibilidade de reinvenção desses espaços;

- objeto hiperterritorializado: reprodução persistente de modelos institucionais e psicológicos, na tentativa de impedir a configuração de novos espaços que viriam pela afirmação de intensidades reversoras de sentimentos, sentidos institucionais, modos de funcionamento psíquico, etc.

Neste artigo pensamos a função-personagem em duas das obras kafkianas: Metamorfose e Carta ao Pai. Por serem estas obras, como todos os outros escritos de Kafka, rizomáticos, por isso entramos

(...) então por qualquer extremidade, nenhuma vale mais que a outra, nenhuma entrada é privilegiada, mesmo se for quase um beco sem saída, uma estreita passagem, um sifão, etc. Procuraremos com quais outros pontos se conecta aquele pelo qual se entra, por quais cruzamentos e galerias se passa para conectar dois pontos, qual é o mapa do rizoma, e como imediatamente ele se modifica se entrássemos por um outro ponto. (DELEUZE; GUATTARI. 1977, p. 7)

Deleuze e Guattari elegem como entrada para a obra kafkiana a relação entre os retratos e a cabeça inclinada. Esta escolha não é aleatória. A constância no aparecimento desses signos justifica a utilização desta porta para os referidos autores adentrarem o rizoma kafkiano. Vejamos como interpretam os significantes eleitos, a saber: cabeça inclinada/retrato-foto e cabeça levantada/som musical: 
Cabeça inclinada/retrato-foto - Desejo bloqueado, submetido ao submissor, neutralizado, com conexão mínima, lembrança da infância, territorialidade ou reterritorialização e cabeça levantada/som musical - desejo que se ergue, ou se desenfia, e se abre a novas conexões, bloco de infância ou bloco animal, desterritorialização. (DELEUZE; GUATTARI. 1977, p.10) ${ }^{7}$

Entendemos, aqui, o indicador cabeça levantada/som musical como posição ética e $\mathrm{o}$ indicador cabeça inclinada/retrato-foto como posição moral. O primeiro designaria a desterritorialização do desejo, e o segundo, a territorialização ou reterritorialização do desejo. Outro significante por eles analisado é:

Cabeça inclinada/retrato-foto: Dizemos apenas que essa reunião opera um bloqueio funcional, uma neutralização do desejo experimental: a foto intocável, imbeijável, interdita, enquadrada, que não pode mais usufruir a não ser de sua própria visão, como o desejo impedido pelo telhado ou pelo teto, o desejo submetido que não pode mais usufruir a não ser de sua própria submissão. (DELEUZE; GUATTARI. 1977. p.8)

Deleuze e Guattari nos apontam o fio condutor, as conexões que estávamos precisando para mapear as posições morais. Nossa hipótese inicial a esse respeito afirmava que os movimentos reprodutores de normas e leis eram práticas territorializantes, não necessariamente favorecedoras da vida. Os significantes cabeça inclinada/retrato-foto nos mostram a reprodução dos signos estandardizados, pois estão bloqueados desde apenas uma relação de significado, neutralizando assim o devir, territorializando-o, submetendo-o às personagens sempre aos mesmos modos de relação com o mundo. Por isto, alheio ao devir, sempre submisso e usufruindo sua submissão. A análise, assim iniciada, nos leva à questão: qual o motivo dessa submissão? A "lembrança de infância edipiana?" (DELEUZE; GUATTARI. 1977, p.8). Dizemos que, de certa forma, sim, pois estamos marcados pela edipianização. Podemos dizer que:

A lembrança é retrato de família ou foto de férias, com senhores de cabeça inclinada e senhoras de pescoço enfitado. Ela bloqueia o desejo, tira dele decalques, retrata-o sobre estratos, afasta-o de todas as suas conexões. (DELEUZE; GUATTARI. 1977, p.8)

A cabeça inclinada (quando se refere a homens) e o pescoço enfitado (quando se refere às mulheres) são sinalizadores de interdição, de submis-

7 Utilizamos aqui uma formatação diferente da tradução por nós consultada para facilitar a apresentação do conteúdo e formatação do texto. 
são, mostrando assim o caráter edipiano. O retrato é uma forma de reprodução dessa situação, lembrança da interdição do desejo. Este é o motivo pelo qual Gregor em Metamorfose se apega ao quadro da parede, enquanto sua irmã retira suas coisas para outro cômodo da casa. Vamos entender esses signos como referentes ao desejo de interdição, busca de reterritorialização nas disposições edipianas.

Por outro lado,

É curioso como em Kafka a intrusão do som freqüentemente faz a conexão de levantar e erguer a cabeça (...). É, sobretudo, na metamorfose que aparece a distinção entre dois estados de desejo; de um lado quando Gregor se comprime sobre o retrato da senhora vestida de peles e inclina a cabeça para a porta, em um esforço desesperado para conservar alguma coisa em seu quarto, que estava sendo esvaziado; de outro lado, quando Gregor sai desse quarto guiado pelo som vacilante do violino, e projeta trepar até o pescoço descoberto de sua irmã (que não usa mais nem gola nem enfeite, desde que perdeu sua situação social). (DELEUZE; GUATTARI. 1977, p.9-10)

O sair, aqui, tem um caráter de desdobramento, início de um novo fluxo; de um ponto de subjetivação; de um movimento de desterritorialização; de reversão de um modo moral de condução do psiquismo para um modo ético de produção existencial. O som do violino de sua irmã é que propicia, que instala o processo desterritorializante. Apresenta-se, desse modo, a associação dessas observações com a nossa segunda hipótese: a desterritorialização é favorecedora da vida, porque recria o espaço social e psicológico (saída do quarto, rumo à sala). O projetar-se ao pescoço da irmã tem um sentido que sustenta, nos parece, este processo que podemos chamar de esquizo. O processo esquizo não é marcado pelo interditor (Pai) nem pelo objeto de desejo (Mãe), de uma perspectiva psicanalítica, mas pela irmã de pescoço descoberto (seu contrário é o pescoço coberto, signo de interdição). Podemos dizer que Gregor possui dois modos de integração com seu espaço psicossocial: um territorializante e outro desterritorializante. O primeiro modo é o apego ao território constituído - a repetição do mesmo; e o segundo é o do devir, buscando a configuração de novos espaços psicossociais.

Além dos significantes já apontados, nos ativemos a outro significante: o som emitido pela irmã de Gregor, som que instalou o processo de desterritorialização.

Na Metamorfose, o som intervém inicialmente como um gemido que arrasta a voz de Gregor e mistura a ressonância das palavras; e depois a irmã, no entanto musicista, consegue apenas fazer um violino gemer, incomodada pela sombra dos inquilinos. (DELEUZE; GUATTARI. 1977, p.11)

De acordo com Deleuze e Guattari, devemos lembrar que: 
O que interessa a Kafka é uma pura matéria sonora intensa, sempre em relação com sua própria abolição, som musical desterritorializado, grito que escapa à significação, à composição, ao canto, à fala, sonoridade em ruptura para desprender-se de uma cadeia ainda muito significante. (DELEUZE; GUATTARI. 1977, p.11)

O som desterritorializado, assignificante, faz funcionar em Gregor outros sentidos, que se intensificam, produzindo o desmanchamento de antigos territórios. Não foi a música, mas o som, a causa do movimento de desterritorialização. "Não é uma música composta, semioticamente formada, que interessa a Kafka, mas uma pura matéria sonora" (DELEUZE; GUATTARI. 1977, p.10). Além disso, pudemos analisar a atitude da irmã que, constrangida pelo olhar dos inquilinos, não consegue conferir musicalidade ao que toca. O efeito do olhar dos inquilinos sobre a irmã funciona como um constrangimento à reterritorialização, ao restabelecimento de seus antigos territórios, anteriores à tragédia de Gregor Samsa.

\section{Considerações finais}

Identificamos alguns personagens nas obras de Kafka que nos pareceram interessantes para a análise a que inicialmente nos propusemos. Num primeiro momento, mostramos que certos personagens criados por Kafka são como máquinas de expressão, personagens experimentais. Eles são capazes de ir além de uma

(...) correspondência estrutural entre duas espécies de formas, formas de conteúdo e formas de expressão (...) capaz de desorganizar suas próprias formas, e de desorganizar as formas de conteúdo. (DELEUZE; GUATTARI. 1977, p.43)

Alguns personagens kafkianos são, a nosso ver, como máquinas de expressão de sentidos éticos, e outros, como máquinas de expressão de sentidos morais. O espaço psicossocial esquizÓide constitui-se como movimento Ético, na medida em que despotencializa o agenciamento moral de sua regularidade, isto é, sua potência de repetição. A ação de despotencialização destitui o espaço moral de sua regularidade, subvertendo sua condição ontológica na possibilidade de um vir-a-ser.

A condição ontológica que torna possível o movimento ético como princípio de diferenciação no agenciamento moral é que este se constitui na afirmação ontológica de um vir-a-ser sempre constante. A Ética funciona como vetor que parte de uma situação instituída (Moral) para uma condição outra, uma desterritorialização do instituído, formando um novo sentido de existência. 
A Moral, em oposição à Ética, não tem potência de desterritorialização, pois é em si mesma a própria estaticidade se instituindo como uma repetição de um mesmo espaço psicossocial. O poder moral é de reterritorialização, ou seja, um poder de repetição do instituído.

PELLOSO, R.G. e FERRAZ F., M. G. C. Ethic and moral as ways of production of subjectivity. Trans/Form/Ação, (São Paulo), v.28(2), 2005, p.117-128.

- ABSTRACT: Deleuze e Guattari understands the ideas of Ethics and Moral as movements that produce psychosocial reality or ways of production of the psychosocial life. We try to understand how the ways of psychosocial functioning produce senses and can be caught in the ethical and moral psychosocial practices. We aim to demonstrate, from kafkian literature, the ways of ethical and moral subjectivation.

- KEYWORDS: subject, production of subjectivity, process of subjectivation, ethic and moral.

\section{Referências bibliográficas}

ARNOULD, W; EYSENCK, H.J; MEILI, R. Dicionário de Psicologia. São Paulo: Loyola, 1982. 3v

BAREMBLITT, G. Introdução à Esquizoanálise. Belo Horizonte: Biblioteca do Instituto Félix Guattari, 1998. 123pp. (Col. Esquizoanálise e Esquizodrama).

DELEUZE, G. Crítica e Clinica. São Paulo: 34, 1997. 176p. (Col. TRANS).

DELEUZE, G; GUATTARI, F. Kafka: Por uma Literatura Menor. Rio de Janeiro: Imago, 1977. 127p.

O Anti-Édipo. Rio de Janeiro: Imago, 1976. 514p.

GUATTARI, F; ROLNIK, S. Micropolítica: Cartografia do Desejo. Petrópolis: Vozes, 1986. 327p.

KAFKA, F. Carta ao Pai. Trad. Modesto Carone. São Paulo: Brasiliense. 1990. 79p.

Metamorfose. Trad. Leandro Konder. Rio de Janeiro: Civilização Brasileira. $1969.70 p$.

\section{Bibliografia Consultada}

DELEUZE, G. Conversações. Rio de Janeiro: 34, 1992. (Col. TRANS). 232p.

A Dobra: Leibniz e o Barroco. Campinas, SP: Papirus, 1991. 212 p.

Espinosa e os Signos. Porto, Portugal: Rés. 1970. 202p.

Lógica do Sentido. São Paulo: Perspectiva, Ed. da Universidade de São Paulo. 1974. 342p. 
DELEUZE, G.; GUATTARI, F. Apresentação de Sacher Masoch. Rio de Janeiro: Taurus. $1983.327 p$.

DELEUZE, G. GUATTARI, F. O Que é a Filosofia? Rio de Janeiro: 34, 1992, 288p. (Col. TRANS).

DELEUZE, G. GUATTARI, F. Mil Platôs: capitalismo e esquizofrenia. Rio de Janeiro: 34, 1996. 5v. (Col. TRANS).

GUATTARI, F. Caosmose: um novo paradigma estético. Rio de Janeiro: 34, 1992. 208p. (Col. TRANS)

KAFKA, F. A Muralha da China. São Paulo: Nova Época. 142p.

KAFKA, F. O Jejuador. Rio de Janeiro: Civilização Brasileira. 1969.

KAFKA, F. O Processo. São Paulo: Abril Cultural, 1982.

KAFKA, F. O Castelo. São Paulo: Abril Cultural, 1982.

LOPES, P. C. Pragmática do Desejo: Aproximação a uma teoria clínica em Félix Guattari e Gilles Deleuze. São Paulo, 1996.159. (Mestrado em Psicologia Clínica) Pontifícia Universidade Católica - PUC.

MACHADO, R. Deleuze e a filosofia. Rio de Janeiro: Graal, 1990. 242p.

NIETZSCHE, F. Obras Incompletas. São Paulo: Abril Cultural, 1983. 416p. (Col. Pensadores) 